\title{
Research on Risk Management and Response in the Process of Labor Dispatching Management
}

\author{
Jianding Zhu ${ }^{1, a_{*}}$, Xueying Yang ${ }^{2, b}$ and Jiwei Yang ${ }^{3, c}$ \\ ${ }^{1,2}$ Southwest forestry university, yunnan, China \\ ${ }^{3}$ Yunnan engineering vocational college yunnan, China \\ a*529147431@qq.com, ${ }^{\mathrm{b}} 154057708 @ q q . c o m,{ }^{\mathrm{c}} 122715917 @ q q . c o m$
}

\section{Keywords: Labor Dispatching; Management Risk; Response}

\begin{abstract}
Labor dispatching is a kind of special recruitment mode along with the reformation of government institutions and development of organizational capacity. Labor dispatching has these features such as flexibility, short, and low cost, etc. compared with formal employment. The risk of management also will increase with development of organizational capacity. Management risks of labor dispatching include the legal risks, moral risk, uncertainty risk and social exclusion risk; so the enterprises must set up the consciousness of risk and effective system of being on guard of risks. But in practice, enterprises usually can not cope with the risk in labor dispatching alone. Social Structure and system are the main sources of risk which labor dispatching units have to face. Therefore, ability to cross-border manage complex object based on social responsibility is the quality requirement for labor dispatching labor unit dealing with risk.
\end{abstract}

\section{Introduction}

In recent years, with the development of government institutions, some government departments and institutions usually adopt labor dispatching because of limited establishment in employment. Labor dispatch is also known as "labor dispatching", under this mechanism, labor dispatch units sign labor contracts with laborers, and laborers are dispatched to labor employment units, and laborers shall abide by the regulations and management of the labor employment units. At present, most enterprises adopt labor dispatching, which is a common form of employment because of manpower shortage. Labor dispatching has been a hot topic in human resource management. In existent researching files, the focus of research on labor dispatching is on views of law and institution, for example, some point of view focus on legal management(zhang huiqin, shen tongxian, 2013; zheng shangyuan, tu yongqian,2014,etc.); some point of view focus on legal losition (dong baohua, 2013;ren jiaju, 2014), some point of view focus on management system(zhang xinmin, 2012; yin minsheng, 2014), some point of view focus on rights protection and equal pay for equal work(zhou guoliang, 2012,yang haonan, 2014). Some studies also discuss the practice of labor dispatch from the analysis of the current situation, problems and Countermeasures. For the risk of labor dispatch, most scholars focus on the analysis of legal risk; and they are mainly for labor dispatch disputes. With all kinds of social organizations to hire more labor dispatch workers, when it still faces the moral differences more obvious in the management of legislation, regulation and system, the practice of labor dispatch inevitably involved in the complex risk contradiction. How to effectively identify the various risks in the labor dispatch is a realistic problem to be overcome.

The management risk of labor dispatching refers to the management risk caused by the principal-agent relationship, asymmetric information, and the application of law. The labor dispatch process will involve the management of complex relationships: the first is the relationship between labor dispatching units and the labor employing units; the second is the relationship between the dispatched workers and labor employing units; the third is the relationship between dispatched workers and labor dispatching units; the fourth is the relationship between dispatched workers and formal employees. To some extent, these relations affect the network and boundaries of organization and management. 
As a popular mode of employment, labor dispatch has impacted the traditional organization management. On the one hand the boundary of organizational management is expanded, so the labor dispatch require the organization to clear its own management authority; On the other hand, the traditional relationship network in the organization needs to be reconstructed, and the labor dispatch makes the members of the organization diversification and diversification, a multi-center management concept is required to introduce the organization management process.

Management Risk of labor Dispatch. In the developed modernity, the social production of wealth is accompanied systematically by the social production of risk". In order to avoid the surge in labor costs, and to reduce the risk of the organization mechanism, some organizations adopt labor dispatch, but which causes new management risk and changes the original characteristics with the transition of field in human resources management[2].

Legal Risk. The legal risk of labor dispatching is mainly caused by the legal gap between "theoretical labor contract law" and "practical labor contract law". Although China's "labor contract law" has clearly defined the signing of the contract, but some of the labor dispatch units will take the "selective responsibility" when they sign a labor contract with the dispatched workers, and some factors closely related to the interests of the dispatched employees have not been settled in the labor contract well. Employees are hard to be compensated for their loss in the event of labor disputes. Especially in some high-risk industries, labor dispatched workers have to obtain legal relief at the expense of life for the loss of the occupational disease. If the employer's qualification is not legal, it shall bring about more legal risks of deepening social contradictions. If the subjects are not legitimate, labor dispatch agreement signed is invalid, so the agreement may be recognized as factual labor contract relation rather than labor relations in labor disputes, and the employment risk is increased. The legal risk destroys the social capital of the whole society. Moreover, whether it is dispatching units, or employing units, the two have the responsibility to jointly safeguard the interests of the labor dispatching workers, but the two responsibilities shared in the relevant laws have not been fully defined.

Moral Risk. The dispatching unit (employer) and the employment unit are equal and independent civil subjects, and the two sides play the principal-agent relationship in the process of labor relations. The relationship between the dispatched workers and the employing units is the labor contract relationship; the relationship between dispatching unit and dispatched workers is the principal-agent relationship. The relationship between the three parties increases complexity and uncertainty of management. The uncertainty in the process of labor dispatch is mainly caused by the uncertainty of labor relations.

Whether the dispatching units or the employing units, they must be a "smart buyer" in the process of signing the labor dispatching contract. The employing units shall clearly know the basic human capital of the labor force to be dispatched in the labor contract before paying the service fee and management fee. These factors such as the incompleteness of knowledge and information, the difficulty of predictability, and the scope of possible acts [3]can affect the management decisions of the employing units. In other words, in fact, employing units can not be completely "smart". Under conditions of the asymmetrical information in the management, dispatching units will deliberately hide relative information, and it will have a negative impact on the employing units. Generally speaking, the dispatching units have the right to supervise the dispatched workers, and the employing units have the right to use the labor force. In fact, the employing units will also have the right to supervise the fulfillment of the duties of the workers.

On the surface, this kind of "double management" of the monitoring system will cause "vacuum" phenomenon in management while duty is not very clear between the dispatching units and labor employing units. The moral disagreement between the dispatching units and the employing units is prominent once the labor dispute, and the two sides all will take steps to safeguard their own interests and neglect and even sacrifice the legitimate interests of labor dispatching workers.

Uncertainty Risk. The risk of uncertainty in labor dispatch is mainly caused by the uncertainty of labor relations, the ambiguity of management authority, the ambiguity of the management boundary and the moral disputes of the employment mode. In our country, the Interim Provisions on labor 
dispatch points out that the employing enterprise can only send the service personnel to the temporary, auxiliary and alternative posts, and the dispatched personnel should have the above characteristics. However, in the actual employment process, the phenomenon of the violation of the provisions can be found everywhere.

Part of the labor dispatch staff has been laid off by the original staff accompanied by the reform of China's economic system. "Massive unemployment has been integrated into a new system of employment in the form of a wide variety of inadequate employment, with all the associated risks and opportunities". The uncertainty of the labor organization caused by the identity alienation of dispatched employees, which saves the expenditure of the organization in the long-term human capital investment. The extent to which the employer can manage the labor dispatch workers and the distribution of responsibilities in the management is vague.

In fact, When the labor dispute occurs, who should bear the corresponding responsibility between the dispatching units and employing units, the dispute is relatively large. In the case of labor disputes and labor crisis, the dispatching units should be responsible for what kind of responsibility and the responsibility of employing units in the relevant laws are still controversial. Beck and Ulrich said: "in the risk society, the unknown and unpredictable consequences become the dominant force in history and society"[4]. Therefore, in the process of labor dispatch, we must face the uncertainty of management risk, and have the ability to manage under uncertainty.

The Risk of Social Exclusion. " Unequal pay for equal work" between dispatched workers and formal workers and the social deprivation of the rights of workers and employees may generate risks. These risks are caused by structural and institutional inequalities. In a pluralistic organization, the fair sense of the labor dispatching workers is the formal staff. When the labor dispatched workers and formal employees in the same work under the circumstances of the different wages, bonuses, the labor dispatch workers will have a sense of injustice. Adams said: "when people feel unfair treatment, they will feel the pain, tension and anxiety, and then affect their behavior motivation".[5] When accumulation of unfair sense to a certain extent can not be resolved, it will lead to social contradictions and social conflicts. The dispatched employees in occupation safety and health, social benefits and social status due to structural and institutional inequality has long been the cause of social deprivation, deprivation of labor dispatched employees in a weak position in the process of social stratification. From the point of view of organizational balance and long-term development, any organization is forced to be involved in the social risks caused by the social exclusion of the dispatched workers.

\section{Response to Management Risk in Labor Dispatch Process}

From the above analysis, legal risk is not the only influence factor, moral risk, management risk, uncertainty risk and social exclusion risk all Often exist in the process of labor dispatching. These risks are potential, once triggered which will cause social unrest and conflict. However, it is very important to identify and respond to the risks when many social organizations (both government and enterprises, or institutions)are interested in the use of labor dispatch employees. Employing units must maintain a cautious attitude to avoid the joint and several liabilities arising from the dispatching units' illegal acts in the use of labor dispatch.

Strengthen the Standardized Management of Labor Dispatch. There is a very close relationship between the contradictions, disputes and enforcement of law in the process of labor dispatching. In the labor relations, it is necessary to further standardize the dispatching units' legitimacy, and take an effective way to carry out the qualification review. For the specification of the employment process, it is necessary to clarify the threshold range of temporary, auxiliary and alternative jobs, clear the use of labor dispatch staff positions. Of course, authority between the dispatching units' and the employing units' should be clarified, in order to avoid problems when passing each other, mutually making excuses. In the process of outsourcing, the principal-agent relationship should have a clear system to regulate. Before using in a formal labor dispatch staff, the employing units should examine and verify the dispatching units' qualification, contract validity, remuneration payment, social security policy and 
the implementation of the agreement between the two sides of the rights and responsibilities, and set up the awareness of risk prevention work with the labor dispatch as soon as possible.

Build Interest Expression Mechanism. Most of the workers are laid-off workers or migrant workers. They have the characteristics of weakness in the level of education, employment ability and employment opportunities. Because of the mobility, temporary or seasonal nature of the occupation, their interests are likely damaged. And in the event of labor disputes, the ability to recover is limited. The phenomenon of the damage to the interests of the dispatched workers is related to the social structure and social system of our country. In the face of this institutional obstacle, the individual often is incapable of action. It is often difficult to pry the system itself for individual resistance. Therefore, the establishment of an effective mechanism to express the interests of the dispatched workers, for the dispatch staff, is undoubtedly a firewall. It can provide effective social support for the labor dispatch staff, which has the characteristics of the times. Although our country gives the trade union the responsibility to protect the legitimate rights and interests of the workers, but in reality, the embarrassment of the Union itself can not really implement the task.

Appeal to the Organization's Social Responsibility. The fulfillment of the social responsibility of the organization is inseparable from the public ethics. In addition to the pursuit of their own development goals, from the moral point of view, they should also bear some public responsibility. These responsibilities may not bring benefits to the organization in the short term, but in the long run, it can create social capital for the organization. The moral hazard and the risk of social exclusion should depend on the social responsibility of the organization. If each organization are only from the economic rationality of labor to carry out corresponding management activities, without considering the negative externalization affects their behavior brought to the whole society, then our society will go under non cooperation against society. In the process of labor dispatch, the organizational social responsibility is mainly reflected in the active implementation of the legitimate rights and interests of the dispatched workers, the signing of labor contracts in accordance with the requirements of the law, standardizing the management of the labor process, etc..

Foster Organizational Management Capabilities in Uncertainty. Drucker believes that modern organizations should have the ability to manage under uncertainty. Any organization must be able to effectively realize management performance must improve the ability to take risks. Under the uncertainty, all the organization's original privileges, industry advantages and technical advantages will be vulnerable, the so-called advantages and disadvantages will be meaningless with the arrival of uncertainty. On the face of it, the labor dispatch is only a variety of characteristics of the members of the organization, but in fact it is the performance of the organizational structure changes. With the introduction of labor dispatched employees, the management boundary of the organization extends to the employers and the whole society. The historical factors of the precipitation of the labor dispatching employees are brought into the employing units along with the expansion of the employment process. The labor employing unit must face up to the structural characteristics of the labor dispatched staff and the organizational field.

\section{Conclusion}

As a form of employment in the process of social transformation, the process of labor relations is a process of producing various risks. For the employing units, it is necessary to correctly identify the various risks in the process of employment, and take appropriate measures to prevent and respond to. The employing units should make a scientific diagnosis of the labor dispatching process, and combine with the challenge of the organization to carry out the strategic planning. Although, many organizations use labor dispatch staff to consider short-term gains from the point of view, if the lack of long-term understanding of the labor dispatch, the impact to the organization caused by the management of liquidity is very great. Therefore, the organization should understand the labor dispatch from the strategic height, which is not only the result of the social responsibility of the organization, but also the need for effective management of the labor dispatch staff. 


\section{References}

[1] Ulrich Beck, the "risk society", Yilin press,(2004), p.15.

[2] Liu Dezhu: "Labor Dispatch Legal Risk", "legal Expo", (2014) first.

[3] [Germany] Ulrich Beck, the "risk society", Yilin press, July (2004) edition, p.8.

[4] Liu Shu, deputy editor in chief: management psychology, Ocean University of China press, (2011).08, p.118.

[5] Liu Shu, deputy editor in chief: management psychology, Ocean University of China press, (2011).08, p.118. 